\title{
Clinical presentation of cardiac myxoma in a Singapore national cardiac centre
}

\author{
Phong Teck Lee ${ }^{1}$, MD, Rilong $\underline{\text { Hong }}^{1}$, MD, Philip YK $\underline{\text { Pang}}^{2}$, MD, Yeow Leng $\underline{\text { Chua }}{ }^{2}$, MD, Zee Pin $\underline{\text { Ding }}^{1}$, MD
}

INTRODUCTION Cardiac myxoma is the most common cardiac tumour. In this study, we summarise our 17-year experience with the clinical presentation of cardiac myxoma at National Heart Centre Singapore, Singapore.

METHODS Between January 2000 and December 2016, retrospective data was reviewed for all consecutive patients who underwent surgical resection of cardiac myxoma. Patients' clinical characteristics were reviewed and described.

RESULTS A total of 67 (18 male, 49 female; mean age $53.1 \pm 13.5$ years) patients underwent cardiac myxoma resection. There were 19 (28.4\%) patients with asymptomatic cardiac myxoma. There were no significant differences in gender; body habitus and myxoma size; and haemoglobin, white blood cell or platelet counts between patients with symptomatic and asymptomatic myxoma. However, the number of asymptomatic cardiac myxomas seemed to follow an increasing trend from $19.4 \%$ (period $2000-2008$ ) to $36.1 \%$ (period 2009-2016), suggestive of an 'era effect'.

CONCLUSION In our study, a majority of patients were women, with a wide age range of 18-78 years. The diagnosis of asymptomatic cardiac myxoma was present in $28.4 \%$ of patients, with an increasing trend for incidence over the years. This is possibly due to increased opportunistic screening (with electrocardiography and clinical examination) as well as higher usage of medical imaging.

Keywords: asymptomatic, cardiac myxoma, cardiac surgery, clinical characteristics, echocardiography

\section{INTRODUCTION}

Cardiac myxoma is the most common 'benign' cardiac tumour and may have varying clinical presentations. ${ }^{(1,2)}$ The classic triad of clinical presentation includes: (a) obstructive cardiac symptoms; (b) embolic signs and symptoms; and (c) constitutional or systemic manifestations. ${ }^{(3)}$ Although the identification of cardiac masses is usually made using imaging, the final diagnosis of cardiac myxoma is confirmed following surgical resection of the cardiac tumour and histopathological assessment of the sample.

The exact incidence of asymptomatic cardiac myxoma is difficult to ascertain due to inclusion bias and heterogenic populations in single-centre studies. Previous studies on asymptomatic cardiac myxoma have documented a wide range of incidence rates, ranging from $0 \%$ to $25 \% .^{(1,3-7)}$ To the best of our knowledge, local data on cardiac myxoma is currently lacking. The aim of the present study was to describe the incidence and clinical features of cardiac myxoma in our local Singapore population.

\section{METHODS}

Data was reviewed for all consecutive patients who underwent surgical resection of cardiac myxoma at National Heart Centre Singapore (NHCS), Singapore, from January 2000 to December 2016. For all patients, the diagnosis of cardiac myxoma was confirmed by histopathological assessment. The patients' medical records were reviewed, and data concerning clinical presentation, diagnostic methods and postoperative course was collected. The cubic measurement of the histopathological sample was calculated as the myxoma size.
Characteristics of symptomatic and asymptomatic patients were compared using IBM SPSS Statistics version 22 (IBM Corp, Armonk, NY, USA). Descriptive statistics were presented as means with standard deviations for continuous variables, unless otherwise specified. Continuous variables were analysed using $t$-test. Categorical data was presented as absolute numbers with percentages and analysed using chi-square test. For all tests, $\mathrm{p}<0.05$ was considered to be statistically significant.

Our study was reviewed and approved by the local institutional review board (CIRB 2016/2379).

\section{RESULTS}

The study comprised 67 cardiac myxoma surgeries in 66 consecutive patients (Table I) - one patient had recurrent cardiac myxoma. There were 18 (26.9\%) men and 49 (73.1\%) women, with a median age of $53.1 \pm 13.5$ (range 18-78) years.

Of the 67 myxomas, 59 (88.1\%) were located in the left atrium and $8(11.9 \%)$ were located in the right atrium. No myxomas were found in other cardiac chambers apart from the atria. The median myxoma size was 30 (range $0.2-405.3$ ) $\mathrm{cm}^{3}$.

There were no significant differences in gender, body size, myxoma size, and haemoglobin, white blood cell or platelet counts between the symptomatic and asymptomatic groups.

A majority of patients were symptomatic at the time of diagnosis (48/67 patients, $71.6 \%$ ). Among these patients, the most common symptoms were dyspnoea (19/48 patients, 39.6\%), ischaemic stroke (15/48 patients, $31.3 \%$ ) and palpitations (8/48 patients, $16.7 \%$ ) (Table II). The median time delay to diagnosis

${ }^{1}$ Department of Cardiology, ${ }^{2}$ Department of Cardiothoracic Surgery, National Heart Centre Singapore, Singapore

Correspondence: Dr Lee Phong Teck, Consultant, Department of Cardiology, National Heart Centre Singapore, 5 Hospital Drive, Singapore 169609. lee.phong.teck@singhealth.com.sg 
Table I. Clinical characteristics of patients with symptomatic and asymptomatic cardiac myxomas.

\begin{tabular}{|c|c|c|c|c|}
\hline \multirow[t]{2}{*}{ Variable } & \multicolumn{3}{|c|}{ No. (\%) } & \multirow[t]{2}{*}{ p-value } \\
\hline & $\begin{array}{l}\text { All cardiac myxoma } \\
(n=67)\end{array}$ & $\begin{array}{l}\text { Asymptomatic myxoma } \\
(n=19)\end{array}$ & $\begin{array}{l}\text { Symptomatic myxoma } \\
(\mathrm{n}=48)\end{array}$ & \\
\hline Age of resection* (yr) & $53.1 \pm 13.5$ & $57.1 \pm 12.1$ & $51.6 \pm 13.9$ & 0.532 \\
\hline Male gender & $18(26.9)$ & $6(33.3)$ & $12(66.7)$ & 0.591 \\
\hline \multicolumn{5}{|l|}{ Location of myxoma } \\
\hline Right atrium & $8(11.9)$ & $4(50.0)$ & $4(50.0)$ & \\
\hline Weight* (kg) & $62.2 \pm 15.1$ & $64.6 \pm 13.1$ & $61.2 \pm 15.9$ & 0.590 \\
\hline Height* (cm) & $157.6 \pm 10.8$ & $158.0 \pm 10.0$ & $156.0 \pm 10.7$ & 0.733 \\
\hline Body mass index* $\left(\mathrm{kg} / \mathrm{m}^{2}\right)$ & $23.0 \pm 5.5$ & $24.6 \pm 3.2$ & $25.2 \pm 6.2$ & 0.440 \\
\hline Myxoma size ${ }^{\dagger}\left(\mathrm{cm}^{3}\right)$ & $30(0.2-405.3)$ & $28.9(0.6-405.3)$ & $30(0.2-279.7)$ & 0.336 \\
\hline Total white blood cell count* (× 10\%/L) & $8.0 \pm 2.1$ & $8.0 \pm 2.4$ & $8.0 \pm 2.0$ & 0.485 \\
\hline Platelet count* (× 10\%/L) & $312 \pm 84$ & $303 \pm 61$ & $302 \pm 92$ & 0.428 \\
\hline \multicolumn{5}{|l|}{ NYHA class } \\
\hline 1 & $50(74.6)$ & $19(38.0)$ & $31(62.0)$ & \\
\hline 2 & $16(23.9)$ & $0(0)$ & $16(100.0)$ & \\
\hline 3 & $1(1.5)$ & $0(0)$ & $1(100.0)$ & \\
\hline
\end{tabular}

Data presented as *mean \pm standard deviation and tmedian (range). NYHA: New York Heart Association Functional Classification

of cardiac myxoma was one month, with the longest time delay of five years in a patient with palpitations.

Table III describes the diagnostic frequency of incidental asymptomatic cardiac myxoma. In total, there were 19 $(28.4 \%)$ asymptomatic cardiac myxoma. A majority (11/19 patients) were diagnosed incidentally during imaging studies for unrelated reasons, such as oncology surveillance (Fig. 1), cardiac preoperative assessment for non-cardiac surgery, and routine health and visa screenings. Of these, four myxomas were diagnosed from preoperative echocardiography, four from computed tomography scanning and three from chest radiography. Three each were diagnosed from abnormal electrocardiogram and cardiac examination during routine followup with a general practitioner. A single case of recurrent cardiac myxoma was diagnosed during echocardiographic surveillance. Finally, one patient experienced profound systemic hypotension during induction of anaesthesia, wherein a cardiac myxoma was discovered during the post-event evaluation.

There were a total of 31 cardiac myxomas during 2000-2008, among which 6 (19.4\%) were asymptomatic, compared with 13 (36.1\%) out of 36 asymptomatic cardiac myxomas during 2009-2016.

Morbidity and mortality data was available for 62 of 67 cardiac myxomas (Table IV). Approximately $72.6 \%$ (45/62) of patients had no postoperative complications. In approximately $27.4 \%(17 / 62)$ of patients, the complications were arrhythmia (13/62 patients, $21.0 \%$ ), postoperative infection (3/62 patients, $4.8 \%$; of which two were wound site infections and one was attributed to urinary tract infection), and large circumferential pericardial effusion in one patient that required relook sternotomy.

The median length of stay was 8.5 days. In-hospital mortality was $1.6 \%$ (1/62 resections). Cause of death was intestinal ischaemia.
Table II. Symptoms and time delay to diagnosis in patients with symptomatic cardiac myxomas.

\begin{tabular}{|l|l|}
\hline Variable & No. $(\mathbf{\%})$ \\
\hline Any symptom* $(\mathbf{n}=\mathbf{6 7})$ & $48(71.6)$ \\
\hline Cardiac symptom $(\mathbf{n}=\mathbf{4 8})$ & $32(66.7)$ \\
\hline Breathlessness/dyspnoea & $19(39.6)$ \\
\hline Palpitation & $8(16.7)$ \\
\hline Chest pain & $7(14.6)$ \\
\hline Cough & $6(12.5)$ \\
\hline Syncope & $1(2.1)$ \\
\hline Embolic symptom $(\mathbf{n}=\mathbf{4 8})$ & $15(31.3)$ \\
\hline Systemic symptom $(\mathbf{n}=\mathbf{4 8})$ & $5(10.4)$ \\
\hline Time delay to diagnosis ${ }^{\dagger}$ (mth) & 1 mth (0 day-5 yr) \\
\hline
\end{tabular}

*Patients may have multiple symptoms. †Data presented as median (range).

Table III. Diagnostic frequency in patients with asymptomatic cardiac myxomas $(n=19)$.

\begin{tabular}{|lll|}
\hline Variable & \multicolumn{2}{c|}{ Incidental diagnosis } \\
\cline { 2 - 3 } & $\begin{array}{l}\mathbf{2 0 0 0 - 2 0 0 8} \\
(\mathbf{n}=\mathbf{6})\end{array}$ & $\begin{array}{l}\mathbf{2 0 0 9 - 2 0 1 6} \\
\mathbf{( n = 1 3 )}\end{array}$ \\
\hline $\begin{array}{l}\text { Preoperative echocardiography } \\
\text { Computed tomography for other } \\
\text { disease management }\end{array}$ & $1(33.3)$ & $2(15.4)$ \\
\hline Abnormal chest radiography & $3(50.0)$ & $3(23.1)$ \\
\hline $\begin{array}{l}\text { Electrocardiogram abnormality (e.g. left } \\
\text { atrial enlargement, arrhythmias) }\end{array}$ & $0(0)$ & $3(23.1)$ \\
\hline $\begin{array}{l}\text { Abnormal cardiac examination } \\
\text { (e.g. murmurs) }\end{array}$ & $0(0)$ & $3(23.1)$ \\
\hline $\begin{array}{l}\text { Echocardiography surveillance } \\
\text { Haemodynamic collapse following } \\
\text { anaesthesia }\end{array}$ & $0(0)$ & $1(7.7)$ \\
\hline
\end{tabular}



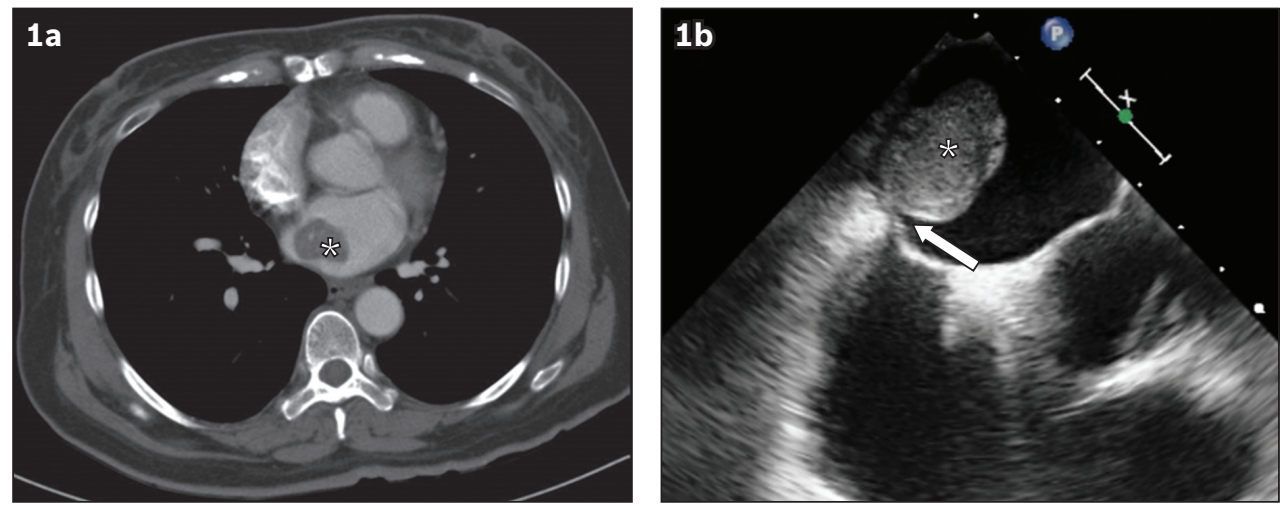

Fig. 1 (a) CT image shows incidental diagnosis of asymptomatic cardiac myxoma (asterisk) upon imaging ordered for surveillance of renal cell carcinoma. (b) Transoesophageal echocardiogram shows a large-sized $(2.6 \mathrm{~cm} \times 2.0 \mathrm{~cm}$ ), echodense, homogeneous mass (asterisk), with short stalk attachment (arrow) to the interatrial septum, consistent with features of cardiac myxoma.

Table IV. Postoperative complications in patients with symptomatic and asymptomatic cardiac myxomas $(n=62) . *$

\begin{tabular}{|llll|}
\hline Postoperative complication & \multicolumn{2}{c|}{ No. (\%) } & Combined $(\mathbf{n}=\mathbf{6 2})$ \\
\cline { 2 - 4 } & Asymptomatic myxoma $(\mathbf{n}=\mathbf{1 8})$ & Symptomatic myxoma $(\mathbf{n}=\mathbf{4 4})$ & $1(1.6)$ \\
\hline Mortality & $0(0)$ & $1(2.3)$ & $13(21.0)$ \\
\hline Arrhythmia & $4(22.2)$ & $9(20.5)$ & $2(3.2)$ \\
\hline Wound infection & $1(5.6)$ & $1(2.3)$ & $3(4.8)$ \\
\hline Pleural/pericardial effusion & $1(5.6)$ & $2(4.5)$ & $45(72.6)$ \\
\hline No complication & $14(77.8)$ & $31(70.5)$ & 8.5 \\
\hline Median length of stay (day) & & & 6 \\
\hline Total & 8 & 9 & \\
\hline After surgery & 6 & 6 & \\
\hline
\end{tabular}

*Only 62 of 67 patients were included due to missing data among patients prior to 2001. †Patients may have multiple symptoms.

\section{DISCUSSION}

In this study, we presented our 17-year experience of cardiac myxoma at a national tertiary cardiac centre in Singapore. Myxoma is the most common primary cardiac tumour, which frequently occurs in middle age and is more common in women than men. ${ }^{(8-10)}$ From our data, the mean age of patients was 53.1 \pm 13.5 years at the time of surgery. Cardiac myxoma was almost three times more common in women than men in our study. The ratio of left atrium-to-right atrium myxoma was approximately 7:1. These findings were comparable with prior studies. ${ }^{(6,7,9)}$

In the published literature, the reported incidence of asymptomatic cardiac myxoma varies widely, between $0 \%$ and $25 \% .^{(1,3-7)}$ These figures were derived from single-centre studies. As such, the results would be influenced by inclusion or referral bias, as well as local expertise. In the present study, the incidence of asymptomatic cardiac myxoma was $28.4 \%$. To the best of our knowledge, this incidence is higher than in previously reported series.

Although there are probably multifactorial reasons, this trend appears to point towards a possible 'era effect'. The incidence of asymptomatic cardiac myxoma seems to have increased from $19.4 \%$ during $2000-2008$ to $36.1 \%$ during 2009-2016. This 'era effect' trend also found support in an earlier study of 57 patients that compared myxoma diagnosed during the periods 1978-1987 and 1988-1997.(6) This earlier study also reported an increasing trend of asymptomatic myxoma detection from $7 \%$ to $26 \%$.
In our opinion, the true incidence of atrial myxoma is difficult to ascertain and unlikely to have changed significantly over this period. Rather, our findings likely represent a better detection rate of asymptomatic cardiac myxoma. We propose that this was due to increased opportunistic screening (by electrocardiography and clinical examination) and higher usage of medical imaging. In our study, no patient with asymptomatic cardiac myxoma during 2000-2008 was detected through electrocardiography or routine clinical examination when compared with six patients during 2009-2016. In addition, computed tomography scanning was responsible for detecting one asymptomatic cardiac myxoma during 2000-2008 when compared with three such myxomas during 2009-2016. This finding was corroborated by the increasing usage of preoperative echocardiographic assessments at our centre. According to our hospital records, in 2011, there were only 176 such studies, in comparison with 884 studies in 2016.

There is a large variation in the size of cardiac myxomas reported in the literature. In our study, we estimated myxoma size using cubic measurement of the histopathological tissue obtained during surgical resection. Other studies have reported the longest linear measurement in a single dimension, ${ }^{(3,7)}$ two dimensions ${ }^{(9)}$ and three dimensions. ${ }^{(6)}$ The lack of standardised methodology for cardiac myxoma measurement thus makes comparison between these studies difficult. However, in our study, there was no significant association between myxoma size and symptoms for 
symptomatic and asymptomatic patients $(p=0.336)$. This was consistent with published data as well. ${ }^{(6)}$

Although perioperative morbidity was up at $27.4 \%$, these were mainly on account of arrhythmia (13/67 myxoma; $21.0 \%$ ). In our study, in-hospital mortality was $1.6 \%$, which was comparable to in-hospital mortality of less than $5 \%$ reported by other studies. ${ }^{(9,10)}$

The recurrence rate after myxoma resection has been reported to be lower than $5 \% .{ }^{(9-12)}$ In our series, 1 (1.5\%) patient with recurrent myxoma was diagnosed with Carney complex. This may perhaps be an underestimation due to the nature of retrospective data analysis, with some patients being lost to follow-up.

Our study had several limitations. Being a single-centre study, our results may not be generalisable to all other centres. Secondly, this was a retrospective observational study, with inherent bias in data collection.

In conclusion, we retrospectively reviewed 67 patients with surgically removed cardiac myxoma during a 17-year period at our Singapore centre. The higher rate of diagnosis of asymptomatic cardiac myxoma suggested an 'era effect' that may not have been caused by true increase in incidence. Resection of cardiac myxoma is a low-risk procedure associated with excellent outcomes and can be considered even for asymptomatic patients.

\section{REFERENCES}

1. Blondeau P. Primary cardiac tumors--French studies of 533 cases. Thorac Cardiovasc Surg 1990; 38 Suppl 2:192-5.

2. Reynen K. Cardiac myxomas. N Engl J Med 1995; 333:1610-7.

3. Pinede $L$, Duhaut $P$, Loire R. Clinical presentation of left atrial cardiac myxoma. A series of 112 consecutive cases. Medicine (Baltimore) 2001; 80:159-72.

4. Miralles A, Bracamonte $\mathrm{L}$, Soncul $\mathrm{H}$, et al. Cardiac tumors: clinical experience and surgical results in 74 patients. Ann Thorac Surg 1991; 52:886-95.

5. Yu SH, Lim SH, Hong YS, et al. Clinical experiences of cardiac myxoma. Yonsei Med J 2006; 47:367-71.

6. Yuda S, Nakatani S, Yutani C, et al. Trends in the clinical and morphological characteristics of cardiac myxoma: 20-year experience of a single tertiary referral center in Japan. Circ J 2002; 66:1008-13.

7. Lee KS, Kim GS, Jung Y, et al. Surgical resection of cardiac myxoma-a 30-year single institutional experience. J Cardiothorac Surg 2017; 12:18.

8. Burke A, Tavora F. The 2015 WHO classification of tumors of the heart and pericardium. J Thorac Oncol 2016; 11:441-52.

9. Bjessmo S, Ivert T. Cardiac myxoma: 40 years' experience in 63 patients. Ann Thorac Surg 1997; 63:697-700.

10. Garatti A, Nano G, Canziani A, et al. Surgical excision of cardiac myxomas: twenty years experience at a single institution. Ann Thorac Surg 2012; 93:825-31.

11. Jones DR, Warden HE, Murray GF, et al. Biatrial approach to cardiac myxomas: a 30-year clinical experience. Ann Thorac Surg 1995; 59:851-6.

12. Centofanti P, Di Rosa E, Deorsola L, et al. Primary cardiac tumors: early and late results of surgical treatment in 91 patients. Ann Thorac Surg 1999; 68:1236-41.

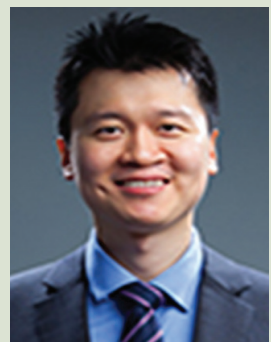

\section{About the First Author}

Dr Lee Phong Teck is a Consultant at the Department of Cardiology, National Heart Centre Singapore. His subspecialty interest is in adult congenital heart disease and cardiac imaging (echocardiography and cardiac magnetic resonance imaging). Dr Lee is actively involved in clinical research and has presented his research at regional and international scientific meetings. He is also a clinical lecturer at NUS Yong Loo Lin School of Medicine, Duke-NUS Medical School, Lee Kong Chian School of Medicine and Singapore Polytechnic. Dr Lee is the programme director for clinical associates and resident physicians at National Heart Centre Singapore. 